\title{
Book Review \\ "In the Shadow of Melting Glaciers. Climate change and Andean Society"
}

\author{
A. Rivera \\ Centro de Estudios Científicos, CECs, Arturo Prat 514, Valdivia, Chile \\ Universidad de Chile, Marcoleta 250, Santiago, Chile
}

Mark Carey: In the Shadow of Melting Glaciers. Climate change and Andean Society, Oxford University Press, 288 pp., ISBN-13: 978-0195396072, EUR 18.99, 2010

The tropical Andes of South America holds a huge number of untold stories about their societies and about the interactions between the locals and their natural beauties. The amazing dynamics of its natural system, including massive and some times shaking mountains, interacting with receding glaciers, unstable proglacial lakes and storming rivers, have had consequences for the population, infrastructure and even for the political system of these Andean societies. This review is related to a book written by Mark Carey, dealing with the Peruvian Andes, the ongoing regional climate changes, consequences of dynamic responses of numerous hanging glaciers existing in this part of the Andes and resultant processes affecting its population and society. These glaciers are providing water resources for the population and their economic activities in many valleys, cities and lowlands, as well as hydroelectricity. The existence of the glaciers attracts many tourists, specially visitors interested in winter sports. Strikeout as it is not necessary, glaciers and glacial lakes are also an important source of hazards for the population and the infrastructure, caused by many natural disasters that occurred in historical times. The history of these disasters have been used by the national and regional authorities for improving planning, defining hazard zones, and organizing public services. However, the social and cultural characteristics of the local populations, their needs for better economic conditions, their attachment to the places they live, among many other reasons, have led to negligence of some of the teachings gained by the disasters. For example, in many cases, after a few years of occurrence of a devastating flood, many destroyed areas have been reoccupied

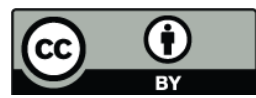

Correspondence to: A. Rivera

(arivera@cecs.cl) and built in, ignoring alert calls of the more conscious officials and local/regional experts. Trying to understand how these disasters have triggered movements within the state, the media and the locals, the book by Carey provides a comprehensive history of the most dramatic glacial lake outburst floods (GLOFs) in the Peruvian Andes, how the population reacted to the consequences of them and how the authorities, scientists and politicians, tried to learn from the events, using the opportunities arising from the destruction the GLOF have provoked, to improve the engineering conditions of the valleys, addressing the more damaging effects, some time with unacceptable delays, and in some cases utilizing these events for personal political purposes, and in others, concealing crucial information from the population. In this context, the book provides an interesting approach, where recent political history of Peru is overlapped with natural disasters and their consequences. Also, this book shows the imbalances between local and national power groups, between peasants and urban population and between wealthy and poor communities, and how these imbalances are reflected in the differentiated responses to natural disasters originated on the changing glaciers. These imbalances were also expressed as a conflict between water users and disaster mitigation plans.

The Peruvian Andes tropical glaciers are experiencing frontal retreats, volumetric shrinkages and higher melting. The main explanation for this ongoing process is the precipitation, humidity and temperature changes, partially in connection to the presence of ENSO (El Niño Southern Oscillation) events. It has been commonly assumed, that receding tropical glaciers were responding to ongoing atmospheric warming, and considering that a future increase in temperature of the order of $4-5^{\circ} \mathrm{C}$ has been projected by climate models based on several IPCC emission scenarios, the impacts on glaciers are expected to be significant (for recent synthesis see George, 2004; Vuille et al., 2008a and b). 
This book is not presenting a detailed account of these glaciers changes, the causes triggering glacier shrinkages or the dynamic responses of the glaciers. They are inputs from the literature, sustaining the main focus of this book; how the natural disasters originated on glacier behaviours are affecting the society. The history of this interaction has been detailed especially for mid XX century when a pessimistic approach was predominant, leading to more recent improvements on glacier research, plans and scientific knowledge, including a shift to viewing glaciers from "hazards" to "resources", especially when considering the meltwater coming from glaciers as fundamental for two water use areas; hydroelectricity and coastal irrigation. This shift is implying for the author an assumption that continued and increasing glacier melt in the future will affect water availability and therefore, water use possibilities will tend to decline. This asseveration is only partially true, because as stated by Juen et al. (2007), in future scenarios of further glacier retreat, mean annual runoff will remain almost unchanged, but the seasonality will intensify considerably, with more runoff during the wet and less runoff during the dry seasons.

At the end of the book, the author is analysing the most recent decades in Peruvian history, in connection to glaciers and political controversies. He is devoting an important part of this last chapter to the implications of the presidency by Alberto Fujimori who was in power between 1990 and year 2000 , and who is now in jail. His presidency was highly controversial for many reasons, one of them being (less dramatic compared to the Human Right abuses), the privatization of Peru's hydroelectric industry and its implications for the glacier research, the mitigation programs and in general the reduction in funding for glacier research. The results of this privatization program are a matter of debate, as very positive achievements were obtained, like the increase in the number of Peruvians access to electricity ( $48 \%$ of people with electricity in 1992 rose to $70 \%$ in 1998). However, the most negative effects were important in terms of social programs and a perception of increasing vulnerability. With the end of Fujimori's regime, some of the more resisted measured of Fujimori were reverted, including the reestablishment of a Glaciology and Hydrological Unit within INRENA in the Ministry of Agriculture, providing more funding for glacier research and mitigation programs, allowing the state to counterbalance the power of hydroelectric companies like Duke Energy.
Glaciers in the context of ongoing climate change affecting the Earth are the focus of intense studies using many different approaches and conceptions. This book is not directly dealing with the scientific research needed for the understanding of glacier wasting behaviour in Peru, but with the implications of these negative changes on a society living under the shadow of these glaciers, utilizing the water resources provided by these glaciers and suffering the consequences of natural disasters taking place in the region, such as the lake outburst floods provoked by huge chunks of ice falling down into proglacial lakes. In this sense, this book is an important contribution for social scientists, interested in the understanding of the complex interactions between nature and society, in a region with long tradition and culture. Also, this book must be used by politicians and local planners interested in doing better things for their communities, prioritizing the safety of the population above the economic profits of investment projects.

I recommend the readers of the HGSS to have a look at this book, especially those interested in doing adaptation, mitigation and hazard research, from the historical and political point of view.

\section{References}

Georges, C.: The 20th century glacier fluctuations in the tropical Cordillera Blanca, Peru, Arct. Antarct. Alp. Res. 36, 100-107, 2004.

Juen, I., Kaser, G., and Georges, C.: Modelling observed and future runoff from a glacierized tropical catchment (Cordillera Blanca, Perú), Global Planet. Change, 59, 37-48, 2007.

Vuille, M., Kaser, G., and Juen, I.: Glacier mass balance variability in the Cordillera Blanca, Peru and its relationship with climate and the large-scale circulation, Global Planet. Change, 62, 1428, 2008a.

Vuille, M., Francou, B., Wagnon, P., Juen, I., Kaser, G., Mark, B. G., and Bradley, R. S. Climate change and tropical Andean glaciers - Past, present and future, Earth Sci. Rev., 89, 79-96, 2008b. 